\title{
A Dynamic Analysis of a Flexible Rotor in Ball Bearings with Nonlinear Stiffness Characteristics
}

\author{
DONG-SOO LEE and DONG-HOON CHOI*
}

Department of Mechanical Design \& Production Engineering Hanyang University, Seoul 133-791, Korea

\author{
(Received 21 March 1996)
}

\begin{abstract}
This paper presents an effective analysis approach for a flexible rotor in ball bearings with nonlinear stiffness characteristics to obtain realistic dynamic behavior results. The ball bearing is modeled in five degrees of freedom and the nonlinear stiffness characteristics of the bearing are completely described as functions of combined loads and spin speed. For dynamic behavior analysis of the nonlinear rotor-bearing system, a transfer-matrix method is iteratively used until the bearing displacements and the shaft displacements at every bearing location converge to the same values. The results show that the nonlinear stiffness characteristics of ball bearings significantly influence system dynamic behaviors and the proposed analysis approach for the nonlinear rotor-bearing system is effective.
\end{abstract}

Keywords: Rotor-bearing system, ball bearing, nonlinear bearing stiffness, critical speed, unbalance response, whirl orbit

\section{INTRODUCTION}

High-Speed rotating machinery with ball bearings, such as aircraft engines and small capacity gas turbines, has been widely used because of easy maintenance, little rotordynamic instability, and low cost. Many authors have shown that a large number of parameters, which include system geometry, disk properties, stiffness distribution of a rotating shaft, and bearing stiffnesses can influence the dynamic behavior of a rotor-bearing system. Amongst them, the ball bearing stiffnesses in particular possess nonlinear characteristics which vary with applied loads and spin speed (Harris [1991]). Recently, many researchers have studied on the analysis of a rotor-bearing system for design and diagnosis. However, their analysis results are difficult to apply because they usually considered the bearing stiffness in radial direction only and disregarded bearing stiffness variation with spin speed and applied loads.

The objective of this study is to propose an effective way of handling the nonlinear stiffness characteristics of ball bearings in the context of the system dynamic behavior analysis to obtain realistic results.

*Corresponding author. Tel.: 82-2-290-0433. Fax.: 82-2-296-1710. 
Two major components necessary to achieve the objective are a ball bearing stiffnesses analyzer and a system dynamic behavior analyzer.

For the analysis of ball bearing stiffnesses, while [1979] calculated radial stiffness by using finite approximation, Gargiulo [1980] presented bearing stiffness formula in radial and axial directions, and Lim and Singh [1990] developed a numerical scheme to compute complete bearing stiffnesses. However, all of them neglected high speed effects such as centrifugal forces and gyroscopic moments of ball elements. Jones [1960] and De Mul et al. [1989] presented general analysis theories for the ball bearing under arbitrary load and speed conditions. In their analyses, however, the inner- and outer-raceway load-deflection factors, centrifugal force, and gyroscopic moment of every ball were assumed to have constant values for all the ball locations. These values, however, actually depend on contact angle values of each ball. This may often cause some errors in ball bearing analysis results under applied load and high speed conditions since contact angle values become quitedifferent from ball location to ball location. To correct this defect, we devise an iterative ball bearing analysis scheme based on Jones' general theory, and then apply it in this study.

For the dynamic behavior analysis of a nonlinear rotor-bearing system, a transfer-matrix method (Murphy and Vance [1983]; Rao [1983]; Vance [1988]) and the proposed bearing analysis scheme are directly integrated and iteratively used until the bearing displacements and the shaft displacements converge to the same values within a specified tolerance at every bearing location.

The next section presents an analysis scheme for obtaining complete nonlinear ball bearing stiffnesses. The numerical procedure for the dynamic behavior analysis of a nonlinear rotor-bearing system is described in section 3 . In section 4 , numerical results are presented to illustrate the nonlinear stiffness characteristics of a high speed ball bearing, the effect of the nonlinear characteristics on the dynamic behavior of a rotor-bearing system, and the usefulness of the proposed analysis approach for a flexible rotor in ball bearings. Finally, concluding remarks are mentioned.

\section{BALL BEARING ANALYSIS}

The relationship between the bearing loads $F=\left\{F_{x}\right.$, $\left.\mathrm{F}_{\mathrm{y}}, \mathrm{F}_{z}, \mathrm{M}_{\mathrm{y}}, \mathrm{M}_{z}\right\}^{\mathrm{T}}$ and the bearing displacements $\delta^{b}=\left\{\delta_{x}^{b}, \delta_{y}^{b}, \delta_{z}^{b}, \theta_{y}^{b}, \theta_{z}^{h}\right\}^{\mathrm{T}}$, as shown in Figure 1, has to be determined for ball bearing analysis. In this study, an iterative bearing analysis algorithm based on Jones' theory [1960] is devised and used to calculate a complete stiffness matrix, and a brief flow chart of the algorithm is shown in Figure 2.

As shown in Figure 2, the input data such as bearing geometry, material, applied loads, and spin speed are specified, and the values of bearing displacements and inner- and outer-raceway contact angles at every ball location $\left(\alpha_{i j}^{I}\right.$ and $\left.\alpha_{o j}^{I}\right)$ are initially assumed at first. In this study, we use the free contact angle value for the initial contact angles. Next, we calculate the inner- and outer-raceway load-deflection factors at each ball location $\left(K_{i j}\right.$ and $\left.K_{o j}\right)$ as well as the centrifugal force and gyroscopic moment of each ball element $\left(C F_{j}, G M_{j}\right)$, and their values are fixed as constant during the process of the inner loop. In the inner loop, the contact angles and deformations at each ball location are computed by solving a system of nonlinear algebraic equations (which consists of two compatibility equations and two ball equilibrium equations) with the values of bearing displacements assumed. Having obtained these values, the bearing displacements $\left(\underline{\delta}^{b}\right)$ can be computed by solving a sys-

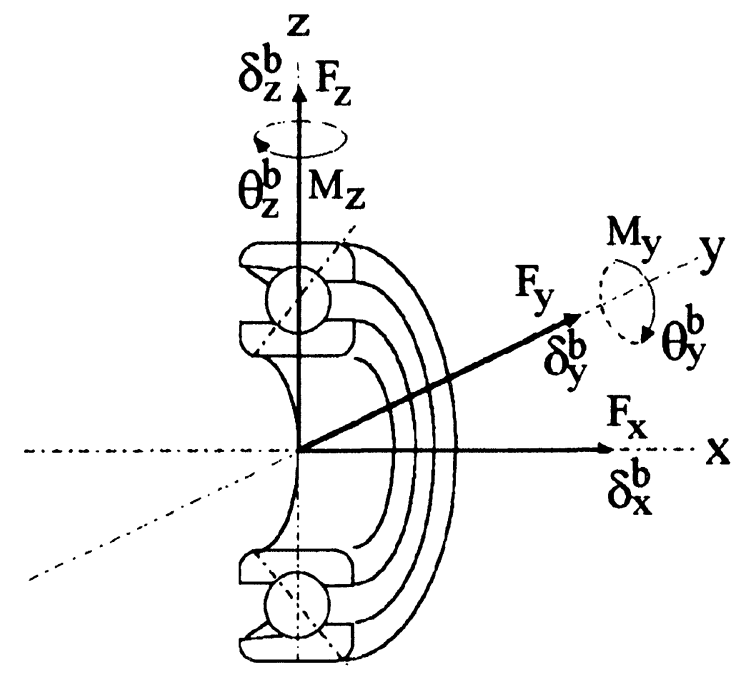

FIGURE 1 Loads and displacements of a ball bearing. 


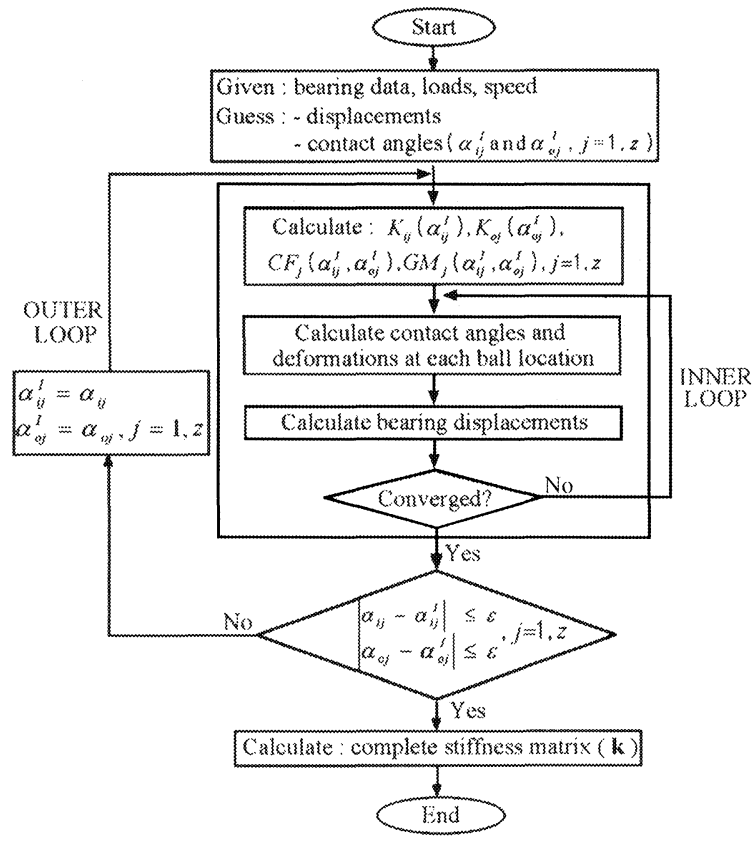

FIGURE 2 Flow chart for ball bearing analysis

tem of five bearing equilibrium equations. This process of the inner loop is repeated until the displacements are converged. Now, the differences between the current contact angle values obtained at the end of the inner loop $\left(\alpha_{i j}\right.$ and $\left.\alpha_{o j}\right)$ and the previous ones ( $\alpha_{i j}^{l}$ and $\alpha_{o j}^{l}$ ) are tested against a specified tolerance $(\varepsilon)$ for every ball location. If they are not within the tolerance, the contact angle values are set to the current ones, and the outer loop process is repeated until con-

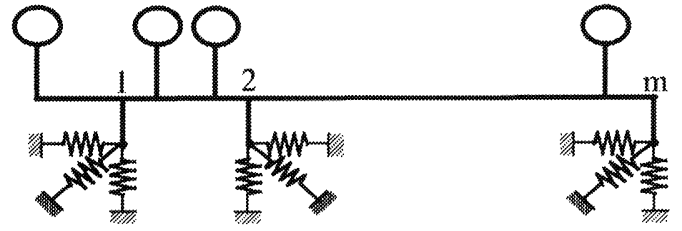

FIGURE 3 Schematic diagram of a rotor-bearing system.

vergence. With the converged results, a complete stiffness matrix is finally calculated by differentiating bearing equilibrium equations.

\section{NONLINEAR ROTOR-BEARING SYSTEM ANALYSIS}

A rotor system supported by ball bearings can be modeled as an assemblage of disks, flexible shaft elements, and bearings as shown in Figure 3. The dynamic behavior of the system is nonlinear since bearing stiffnesses vary with spin speed, applied preload, and transmitted loads due to unbalance. For the anal$y$ sis of the nonlinear rotor-bearing system, an overall procedure is shown in Figure 4.

As shown in Figure 4, bearing and rotor data are specified and a spin speed is given at first. Bearing loads $\left(\underline{\mathrm{F}}_{n}^{b}\right)$, which include an applied preload and loads transmitted from the rotor, and bearing displacements $\left(\underline{\delta}_{l}^{b}\right)$ are also initially assumed at every bearing location. Having the assumed bearing loads

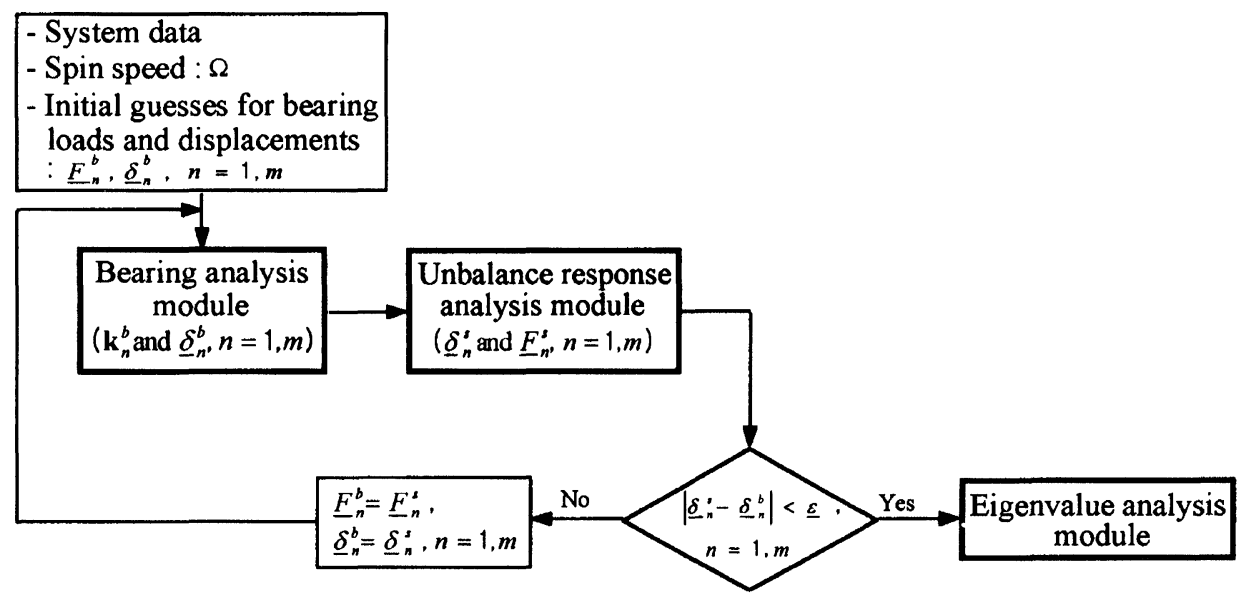

FIGURE 4 Overall procedure for the dynamic analysis of a nonlinear rotor-bearing system. 
and displacements, bearing stiffnesses $\left(\mathbf{k}_{n}\right)$ and displacements $\left(\underline{\delta}_{n}^{b}\right)$ of every bearing are calculated in the bearing analysis module. The calculated bearing stiffnesses $\left(\mathbf{k}_{n}\right)$ are fed into the unbalance response analysis module to compute the shaft displacements $\left(\underline{\delta}_{n}^{s}\right)$ and internal shaft forces $\left(\underline{F}_{n}^{s}\right)$ at every bearing location. Then, the differences between the bearing displacements $\left(\underline{\delta}_{n}^{b}\right)$ and shaft displacements $\left(\underline{\delta}_{n}^{s}\right)$ are compared against a given tolerance for every bearing. If they are not within the tolerance, the bearing loads and displacements $\left(\underline{F}_{n}^{b}, \underline{\delta}_{n}^{b}\right)$ are updated to have the values of the shaft internal forces and displacements $\left(\underline{\mathrm{F}}_{n}^{s}, \underline{\delta}_{n}^{s}\right)$, and the above process is repeated until convergence. Finally, using the bearing stiffnesses $\left(\mathbf{k}_{n}, n\right.$ $=1, \ldots, \mathrm{m}$ ) converged, the eigenvalues of the system at the given spin speed are computed in the eigenvalue analysis module. In this study, the scheme described in the previous section is used for ball bearing analysis and a transfer matrix method (Murphy and Vance [1983]; Rao [1983]; Vance [1988]) for the eigenvalue and unbalance response analyses.

For the dynamic behavior analysis of a nonlinear rotor-bearing system in a range of spin speeds, the above procedure can be repeatedly used to sweep the range.

\section{NUMERICAL RESULTS}

To evaluate the usefulness of the suggested dynamic analysis approach for a nonlinear rotor-bearing sys-
TABLE I Ball bearing specifications

\begin{tabular}{lc}
\hline Number of ball elements & 13 \\
\hline Pitch diameter (mm) & 46.0 \\
Ball diameter (mm) & 9.526 \\
Young's modulus (MPa) & 206000 \\
Initial contact angle (deg.) & 40.0 \\
Outer groove curvature radius $(\mathrm{mm})$ & 4.950 \\
Inner groove curvature radius $(\mathrm{mm})$ & 4.950 \\
\hline
\end{tabular}

tem, a computer program is developed to implement the numerical procedures described in sections 2 and 3 . In the following, the numerical results are presented to illustrate nonlinear stiffness characteristics of a ball bearing and the effect of the nonlinear characteristics on the dynamic behavior of a rotor-bearing system.

\subsection{Ball Bearing Stiffness Analysis}

The specifications of the angular contact ball bearing used in this study are listed in Table I. To investigate the effects of spin speed and loads on bearing stiffnesses, we simulated the variation of bearing stiffnesses within the speed range of 0-40000 rpm under the loads of $F_{x}=1500 \mathrm{~N}, F_{h}=1000 \mathrm{~N}, M_{y}=10$ $\mathrm{N} \cdot \mathrm{m}$.

Simulation results are shown in Figure 5. The variations of radial, coupling, and rotational stiffnesses are plotted as a function of spin speed. Further, the stiffness results analyzed by the proposed scheme are compared with those analyzed by Jones' scheme. As

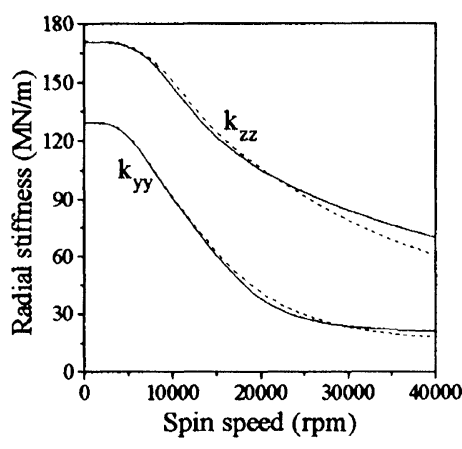

(a)

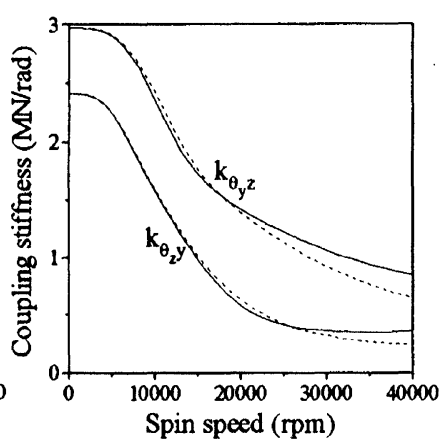

(b)

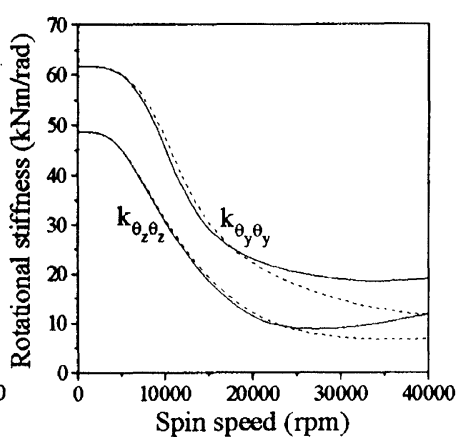

(c)

FIGURE 5 Nonlinear stiffness characteristics of the angular contact ball bearing (- $\longrightarrow$ proposed scheme, .......: Jones' scheme). 


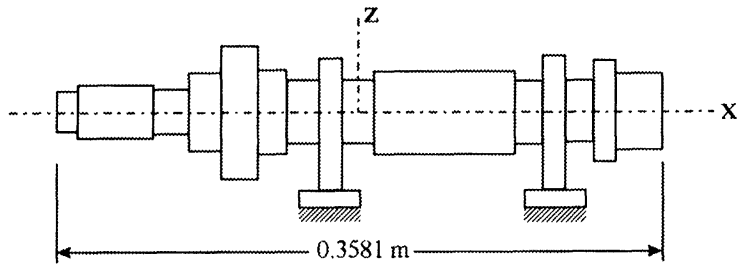

FIGURE 6 A multi-stepped rotor-bearing system.

can be seen in Figure 5, the effect of spin speed on bearing stiffnesses is significant and the stiffness characteristic is anisotropic due to the force in the $\mathrm{z}$ direction and the moment in the y direction. The discrepancy between the results analyzed by the two schemes increases as spin speed increases, because the proposed iterative scheme well considers the effects of centrifugal force and gyroscopic moment of each ball element on bearing stiffness characteristics.

\subsection{Dynamic Behavior Analysis of a Nonlinear Rotor-Bearing System}

In this study, the ball bearing analysis module, the system unbalance response analysis module, and the system eigenvalue analysis module are directly integrated and applied to the dynamic behavior analysis of a multi-stepped rotor which is supported by two angular contact ball bearings as shown in Figure 6 . The shaft with varying cross-sectional area is divided into 18 elements and the bearings of Table I under the preload of $1500 \mathrm{~N}$ in axial direction are located at stations 11 and 15 . One disk with a fixed mass is located at station 5 . The details of rotor configuration data are listed in Table II.

To investigate the effect of nonlinear bearing stiffness characteristics on system critical speeds, the unbalance response with constant bearing stiffnesses and that with nonlinear stiffnesses are obtained and the results are shown in Figure 7 and Figure 8, respectively. The constant bearing stiffness values used here are the ones calculated at the spin speed of $22000 \mathrm{rpm}$, and the unbalance at the disk is assumed as $1.0 \times 10^{-10} \mathrm{~kg} \cdot \mathrm{m}$ in both cases. Comparison of Figure 7 and Figure 8 shows that the discrepancies of the first and the second critical speeds of two results are $14 \%$ and $10 \%$, respectively. Figure 9 shows that the whirl orbit results with nonlinear bearing stiffnesses at $19000 \mathrm{rpm}, 22000 \mathrm{rpm}$, and $24400 \mathrm{rpm}$ are circular. This implies that the isotropic characteristics of the bearings are hardly affected since the forces and moments transmitted by the unbalance are not noticeable compared with the applied preload.

To examine the effect of unbalance magnitude on the dynamic behavior of the nonlinear rotor-bearing system, we analyze system eigenvalues, unbalance response, and whirl orbits with the unbalance of 1.0 $\times 10^{-6} \mathrm{~kg} \cdot \mathrm{m}$, and the simulation results are shown in Figure 10, Figure 11, and Figure 12, respectively. The

TABLE II Multi-stepped rotor configuration data

\begin{tabular}{|c|c|c|c|c|c|c|c|c|c|}
\hline $\begin{array}{l}\text { Element } \\
\text { node } \\
\text { no. }\end{array}$ & $\begin{array}{l}\text { Node } \\
\text { location } \\
(\mathrm{m})\end{array}$ & $\begin{array}{c}\text { Bearing } \\
\& \\
\text { disk }\end{array}$ & $\begin{array}{l}\text { Outer } \\
\text { radius } \\
(\mathrm{m})\end{array}$ & $\begin{array}{l}\text { Inner } \\
\text { radius } \\
(\mathrm{m})\end{array}$ & $\begin{array}{c}\text { Element } \\
\text { node } \\
\text { no. }\end{array}$ & $\begin{array}{l}\text { Node } \\
\text { location } \\
\text { (m) }\end{array}$ & $\begin{array}{c}\text { Bearing } \\
\& \\
\text { disk }\end{array}$ & $\begin{array}{l}\text { Outer } \\
\text { radius } \\
(\mathrm{m})\end{array}$ & $\begin{array}{l}\text { Inner } \\
\text { radius } \\
(\mathrm{m})\end{array}$ \\
\hline 1 & -0.1790 & \multirow{10}{*}{ Disk } & 0.0051 & & 11 & -0.0139 & \multirow[t]{4}{*}{ Bearing } & 0.0127 & \\
\hline 2 & -0.1663 & & 0.0102 & & 12 & 0.0115 & & 0.0152 & 0.0052 \\
\hline 3 & -0.1282 & & 0.0076 & & 13 & 0.0496 & & 0.0152 & 0.0052 \\
\hline 4 & -0.1028 & & 0.0203 & & 14 & 0.0877 & & 0.0127 & \\
\hline 5 & -0.0901 & & 0.0203 & 0.0152 & 15 & 0.1080 & \multirow[t]{6}{*}{ Bearing } & 0.0127 & \\
\hline 6 & -0.0774 & & 0.0330 & & 16 & 0.1258 & & 0.0381 & \\
\hline 7 & -0.0723 & & 0.0330 & 0.0152 & 17 & 0.1360 & & 0.0203 & 0.0152 \\
\hline 8 & -0.0647 & & 0.0254 & 0.0178 & 18 & 0.1664 & & 0.0203 & 0.0152 \\
\hline 9 & -0.0520 & & 0.0254 & & 19 & 0.1791 & & & \\
\hline 10 & -0.0444 & & 0.0127 & & & & & & \\
\hline Disk: & & (m) & & & & $\begin{array}{l}\mathrm{rtia}(\mathrm{kg} \cdot \mathrm{m}) \\
(020\end{array}$ & & $\begin{array}{r}\text { Diametral it } \\
0.0\end{array}$ & $(\mathrm{~kg} \cdot \mathrm{m})$ \\
\hline
\end{tabular}




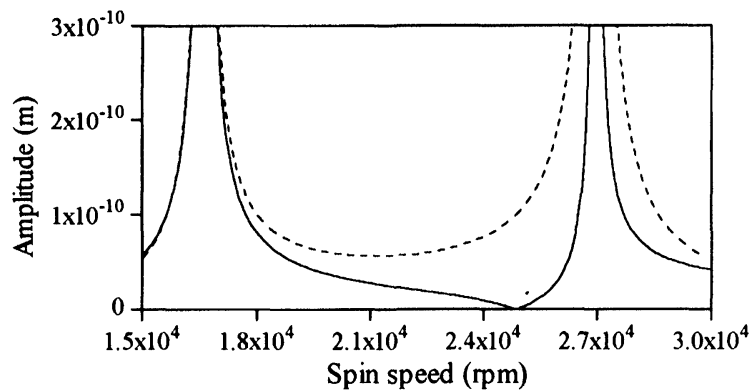

FIGURE 7 Unbalance response results with constant bearing stiffnesses (Unbalance $=1.0 \times 10^{-10} \mathrm{~kg} \cdot \mathrm{m}:-$ Response at the left bearing, ....... Response at the right bearing).

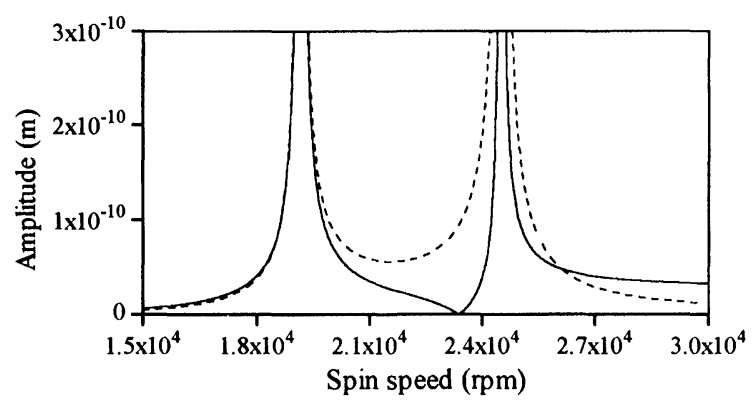

FIGURE 8 Unbalance response results with nonlinear bearing stiffnesses $\left(\right.$ Unbalance $=1.0 \times 10^{-10} \mathrm{~kg} \cdot \mathrm{m}$ : - Response at the left bearing, ....... Response at the right bearing).

comparison of Figure 8 and Figure 11 reveals that the effect of unbalance magnitude on the first and the second forward critical speeds is not noticeable. With relatively large unbalance, however, backward critical speeds appear as shown in Figure 10 and Figure 11. The comparison of Figure 9 and Figure 12 shows that the whirl orbits near the critical speeds become quite elliptical as unbalance magnitude increases.

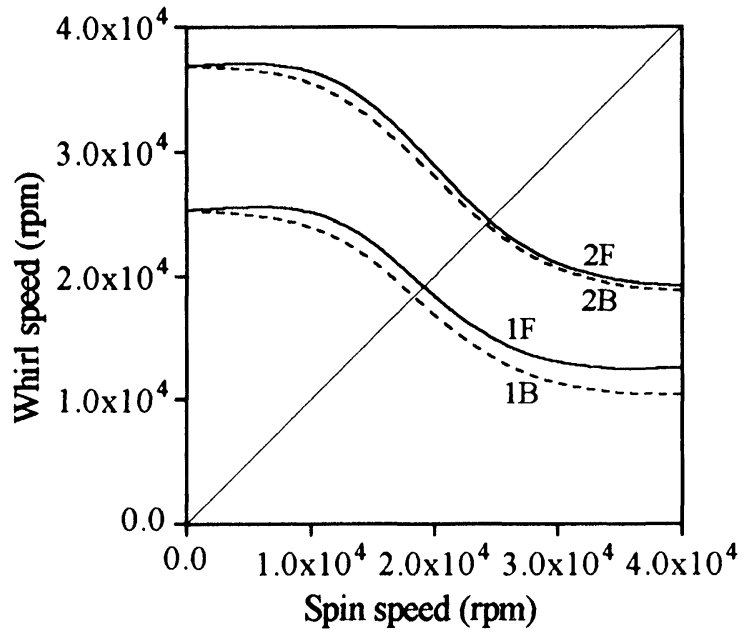

FIGURE 10 Whirl speed map of a multi-stepped rotor-bearing system.

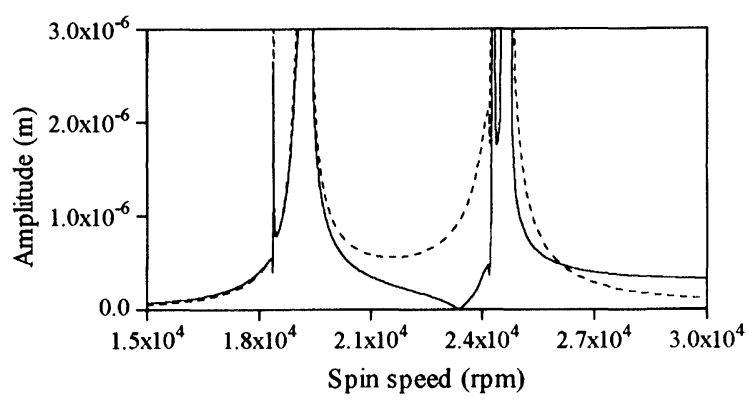

FIGURE 11 Unbalance response results with nonlinear bearing stiffnesses $\left(\right.$ Unbalance $=1.0 \times 10^{\circ{ }^{\circ}} \mathrm{kg} \cdot \mathrm{m}$ : $\longrightarrow$ Response at the left bearing, ....... Response at the right bearing).

This reflects that the bearing stiffness characteristics become anisotropic due to the loads transmitted from the rotating shaft.

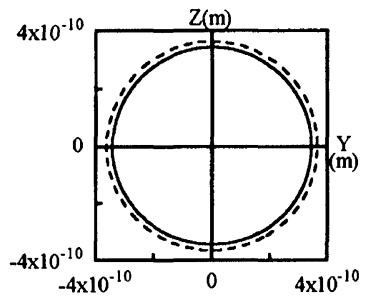

(a) $19000 \mathrm{rpm}$

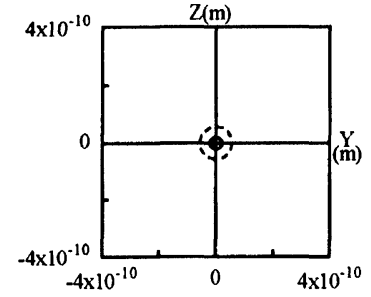

(b) $22000 \mathrm{rpm}$

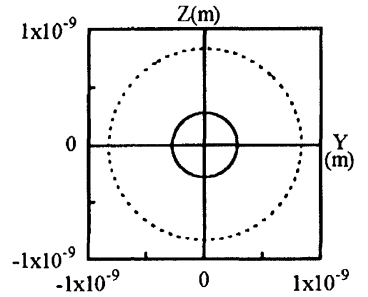

(c) $24400 \mathrm{rpm}$

FIGURE 9 Whirl orbits of nonlinear rotor-bearing system (Unbalance $=1.0 \times 10^{-10} \mathrm{~kg} \cdot \mathrm{m}$ : - Response at the left bearing, ....... Response at the right bearing). 


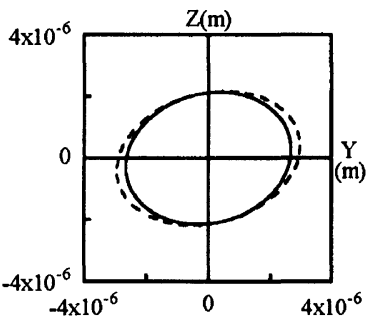

(a) $19000 \mathrm{rpm}$

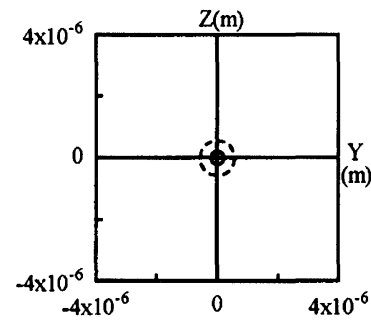

(b) $22000 \mathrm{rpm}$

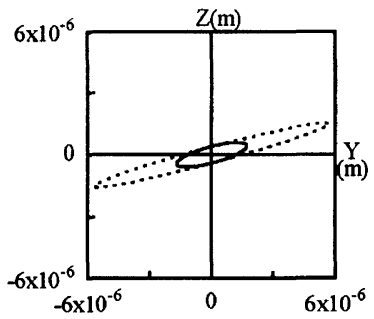

(c) $24400 \mathrm{rpm}$

FIGURE 12 Whirl orbits of the nonlinear rotor-bearing system (Unbalance $=1.0 \times 10^{-6} \mathrm{~kg} \cdot \mathrm{m}$ : - Response at the left bearing, ....... Response at the right bearing).

\section{CONCLUDING REMARKS}

This paper proposes a new approach of directly integrating a ball bearing analyzer and a dynamic behavior analyzer for the dynamic analysis of a nonlinear rotor-bearing system. At first, a numerical scheme for calculating the speed- and load-dependent stiffnesses of a ball bearing is developed in which the dependency of load-deflection factors, centrifugal force, and gyroscopic moment on contract angle values is well regarded. Then, an iterative procedure for analyzing the dynamic behavior of a nonlinear rotorbearing system in a truly integrated fashion is developed and applied to the analysis of a multi-stepped rotor supported by two angular contract ball bearings.

Numerical results demonstrate the importance of including the nonlinear bearing stiffness characteristics for dynamic behavior analysis by showing the discrepancy between the analysis results with nonlinear bearing stiffnesses and those with constant bearing stiffnesses. Comparison of the results also illustrates that the effect of unbalance magnitude on system dynamic behavior can be remarkable.

Even though the suggested analysis approach is applied only to the rotor system supported by ball bearings in this study, we believe that the same approach can be applied to the rotor system supported by sliding bearings.

\section{Acknowledgements}

This study is supported by Turbo and Power Machinery Research Center in Korea Science and Engineering Foundation.

\section{NOMENCLATURE}

$C F$ : centrifugal force $[\mathrm{N}]$

F : load vector

$G M$ : gyroscopic moment [N.m]

$K:$ load-deflection factor $\left[\mathrm{N} / \mathrm{m}^{3 / 2}\right]$

$\mathbf{k}:$ stiffness matrix

$\mathrm{k}_{\mathrm{pq}}$ : stiffness in $\mathrm{p}$ direction due to the load in $\mathrm{q}$ direction

$\mathrm{m}$ : number of ball bearings

$\mathrm{z} \quad$ : number of ball elements

$\Omega \quad:$ spin speed [rpm]

$\underline{\delta}:$ displacement vector

$\alpha \quad$ : contact angle [degree]

$\epsilon \quad$ : specified tolerance for convergence

\section{Superscript}

$b$ : bearing

$I$ : initial guess

$s$ : shaft

\section{Subscript}

$i$ : inner-raceway

$j:$ ball azimuth location

$n$ : ball bearing location

o : outer-raceway

\section{References}

De Mul, J. M., Vree, J. M., and Maas, D. A., 1989. Equilibrium and Associated Load Distribution in Ball and Roller Bearings Loaded in Five Degrees of Freedom While Neglecting Fric- 
tion-Part I: General theory and Application to Ball Bearings, Journal of Tribology, Vol. 111, pp. 142-148.

Gargiulo, E. P., 1980. A Simple Way to Estimate Bearing Stiffness, Machine Design, Vol. 52, pp. 107-110.

Harris, T. E., 1991. Rolling Bearing Analysis: 3rd Edition, John Wiley \& Sons Publishing, New York, pp. 395-399.

Jones, A. B., 1960. A General Theory for Elastically Constrained Ball and Roller Bearing Under Arbitrary Load and Speed Conditions, Journal of Basic Engineering, Vol. 82, pp. 309-320.

Lim, T. C. and Singh, R., 1990. Vibration Transmission Through Rolling Element Bearing, Part I: Bearing Stiffness Formulation, Journal of Sound and Vibration, Vol. 139, No. 2, pp. 179-199.
Murphy, B. T. and Vance, J. M., 1983. An Improved Method for Calculating Critical Speeds and Rotor dynamics Stability of Turbomachinery, Journal of Engineering for Power, Vol. 105, pp. $591-595$.

Rao, J. S., 1983. Rotor Dynamics, John Wiley \& Sons Publishing, New York, pp. 51-85.

Vance, J. M., 1988. Rotordynamics of Turbomachinery, John Wiley \& Sons Publishing, New York.

While, M. F. 1979. Rolling Element Bearing Vibration Transfer Characteristics: Effect of stiffness, Journal of Applied Mechanisms, Vol. 46, pp. 677-684 


\section{ait \\ ENERGY MATERIALS}

M A N E Y publishing

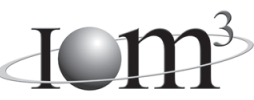

\section{Materials Science \& Engineering for Energy Systems}

Maney Publishing on behalf of the Institute of Materials, Minerals and Mining

The Institute of Materials, Minerals \& Mining

Economic and environmental factors are creating ever greater pressures for the efficient generation, transmission and use of energy. Materials developments are crucial to progress in all these areas: to innovation in design; to extending lifetime and maintenance intervals; and to successful operation in more demanding environments. Drawing together the broad community with interests in these areas, Energy Materials addresses materials needs in future energy generation, transmission, utilisation, conservation and storage. The journal covers thermal generation and gas turbines; renewable power (wind, wave, tidal, hydro, solar and geothermal); fuel cells (low and high temperature); materials issues relevant to biomass and biotechnology; nuclear power generation (fission and fusion); hydrogen generation and storage in the context of the 'hydrogen economy'; and the transmission and storage of the energy produced.

As well as publishing high-quality peer-reviewed research, Energy Materials promotes discussion of issues common to all sectors, through commissioned reviews and commentaries. The journal includes coverage of energy economics and policy, and broader social issues, since the political and legislative context influence research and investment decisions.

\section{CALL FOR PAPERS}

Contributions to the journal should be submitted online at http://ema.edmgr.com

To view the Notes for Contributors please visit: www.maney.co.uk/journals/notes/ema

Upon publication in 2006, this journal will be available via the Ingenta Connect journals service. To view free sample content online visit: www.ingentaconnect.com/content/maney

For further information please contact:

Maney Publishing UK

Tel: +44 (0)113 2497481 Fax: +44 (0)1132486983 Email: subscriptions@maney.co.uk

or

Maney Publishing North America

Tel (toll free): 8662975154 Fax: 6173546875 Email: maney@maneyusa.com

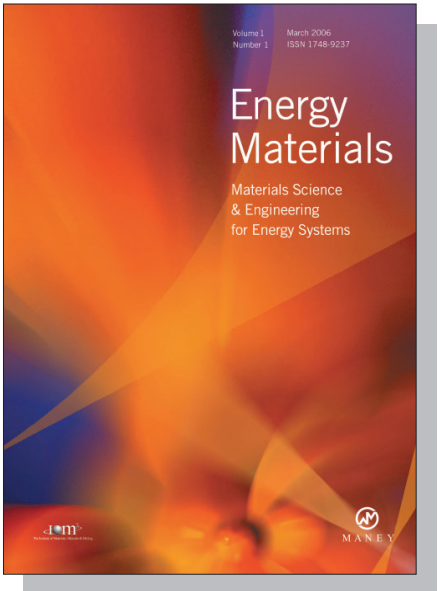

EDITORS

Dr Fujio Abe

NIMS, Japan

Dr John Hald, IPL-MPT, Technical University of Denmark, Denmark

Dr R Viswanathan, EPRI, USA

\section{SUBSCRIPTION INFORMATION}

Volume 1 (2006), 4 issues per year

Print ISSN: 1748-9237 Online ISSN: 1748-9245

Individual rate: $£ 76.00 / U S \$ 141.00$

Institutional rate: $£ 235.00 /$ US $\$ 435.00$

Online-only institutional rate: $£ 199.00 / U S \$ 367.00$

For special $\mathrm{IOM}^{3}$ member rates please email

subscriptions@maney.co.uk

\section{For further information or to subscribe online please visit www.maney.co.uk}



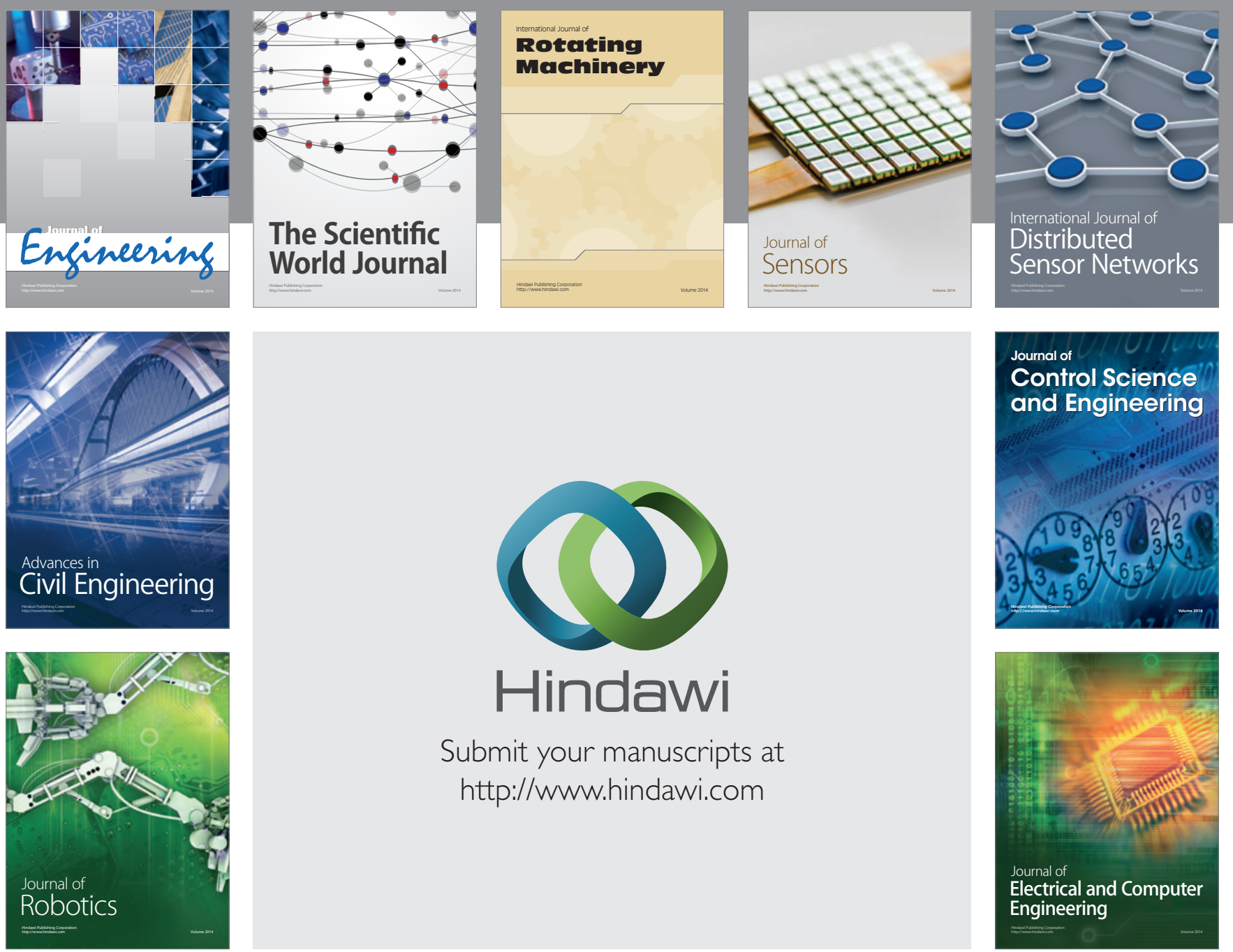

Submit your manuscripts at

http://www.hindawi.com
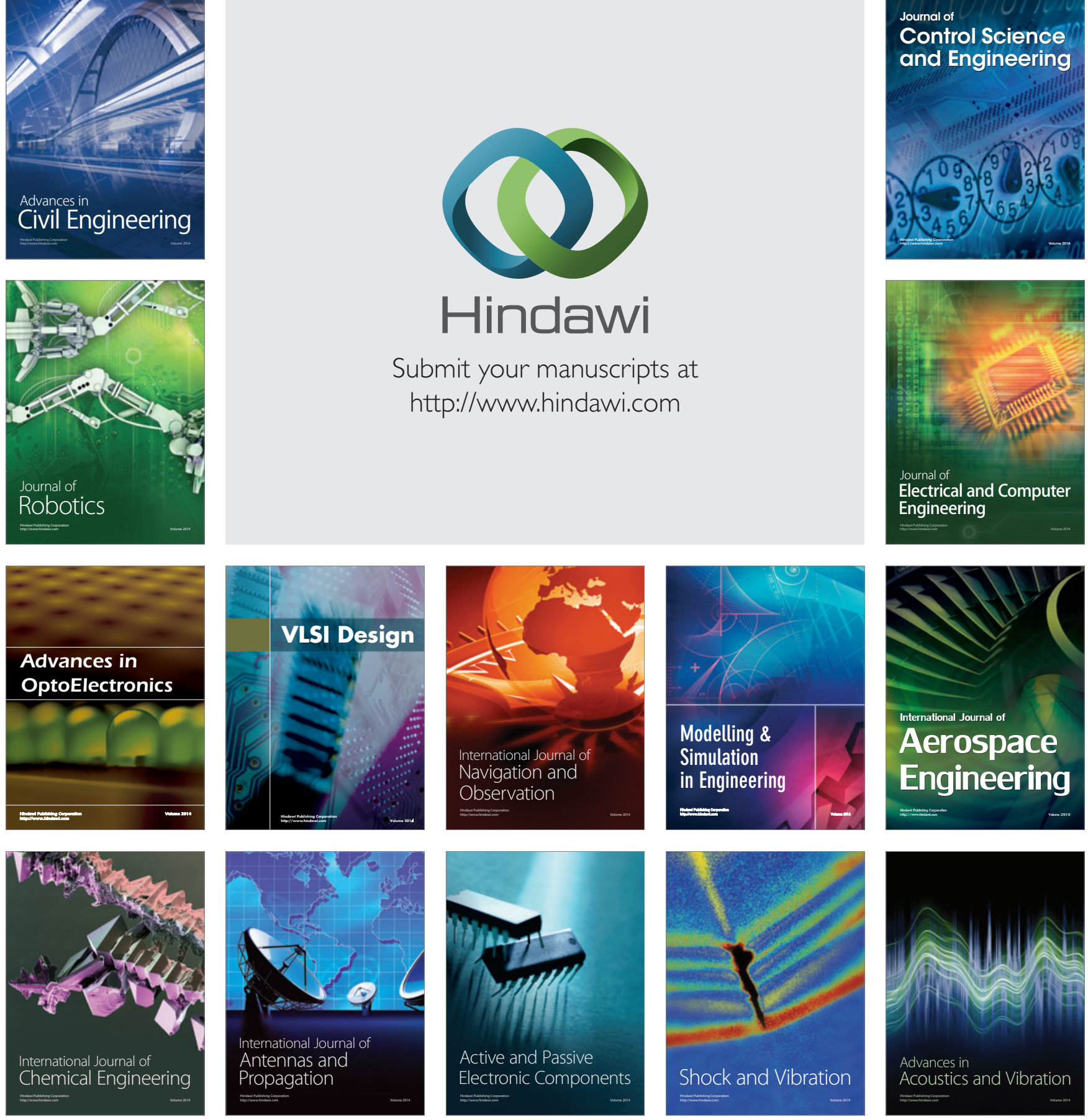